\title{
COMPREHENSIVE STUDY OF ILEOSTOMY AT A TERTIARY CARE MEDICAL COLLEGE HOSPITAL
}

\author{
Hanuman Singh Udawat ${ }^{1}$, Suman Parihar ${ }^{2}$, Pankaj Saxena ${ }^{3}$ \\ ${ }^{1}$ Assistant Professor, Department of General Surgery, Geetanjali Medical College \& Hospital, Udaipur, Rajasthan. \\ ${ }^{2}$ Assistant Professor, Department of General Surgery, Geetanjali Medical College \& Hospital, Udaipur, Rajasthan. \\ 3 Professor, Department of General Surgery, Geetanjali Medical College \& Hospital, Udaipur, Rajasthan.
}

\section{ABSTRACT}

\section{BACKGROUND}

We are working at a tertiary care medical college hospital (Geetanjali Medical College) Udaipur (Rajasthan) India. Conducted a comprehensive study of ileostomy, its varied indications, types, post-operative morbidity and eventual closure of ileostomy. We also analyse all the different aetiopathologies and all surgical aspects associated with ileostomy.

\section{METHODS}

A total of 30 patients undergoing ileostomy for various causes were studied retrospective over a period of 2 yrs. Stomal and nonstomal related complications were analysed. Reversal of stoma usually performed after 8 weeks and complications of reversal were also recorded.

\section{RESULTS}

Typhoid perforation 9 cases (30\%) was the most common pathology, followed by blunt trauma abdomen 6 cases (20\%), malignancy of colon/rectum 4 cases (13.33\%), intestinal obstruction with perforated gangrenous ileum 3 cases (10\%), perforated tubercular ileum 3 cases (10\%), fulminating necrotic colitis 3 cases $(10 \%)$ and mesenteric vascular thrombosis with gangrenous ileum 2 cases $(6.66 \%)$ were observed. Wound sepsis, excessive effluent, skin excoriation, fluid and electrolyte imbalance and chest complication were the commonest; there were 2 cases (6.66\%) of minor anastomotic leak, 1 case (3.33\%) major leak with faecal fistula formation that healed over a period of time. One case (3.33\%) had a sequential surgical complication as fulminant septicemia, ARDS and multi-organ dysfunction, eventually succumbed in ICU on $30^{\text {th }}$ day.

\section{CONCLUSION}

Ileostomy in various surgical situations has proved to be a life-saving act for the patients and a face saving measure for the surgeon; however, one has to accept the eventual morbidity that continues until an ileostomy closure accomplished.

\section{KEYWORDS}

Temporary Loop Ileostomy, Perforation Peritonitis, End Ileostomy, Barrel Ileostomy.

HOW TO CITE THIS ARTICLE: Udawat HS, Parihar S, Saxena P. Comprehensive study of ileostomy at a tertiary care medical college hospital. J. Evolution Med. Dent. Sci. 2016;5(14):659-663, DOI: 10.14260/jemds/2016/151

\section{INTRODUCTION}

An ileostomy is often a rescue option in a number of difficult surgical situations that enables a surgeon and also the patients a smooth sailing subsequently.(1) A spectrum of conditions prevails for opting the ileostomy. There are all kinds of procedure choices as loop ileostomy, end ileostomy, temporary and permanent variety depending upon surgeon's choice and situation.(2,3) In the post-operative period for ileostomy is a bit challenging for the patient as the effluent is copious as well as for the surgeon to devise an optimal management of ileostomy care. For closure of ileostomy there are advocates for an early closure (2 weeks) v/s standard closure after 8 weeks, each one having their own logic and its own pros and cons. We working at a Tertiary Care Medical College Hospital (GMCH), Udaipur, conducted a comprehensive study of ileostomy. It varied indication, types, postoperative morbidity and eventual closure of ileostomy. We also attempted to compare and analyse all the differences and surgical aspects associated with ileostomy.

Financial or Other, Competing Interest: None.

Submission 28-12-2015, Peer Review 28-01-2016,

Acceptance 03-02-2016, Published 18-02-2016.

Corresponding Author:

Dr. Hanuman Singh Udawat,

Q.No: A/S-2, Geetanjali Medicity, Hiran Magri Extn.

Manwa Khera, Udaipur-313002, Rajasthan

E-mail:dr.udawat@rediffmail.com

DOI: $10.14260 /$ jemds/2016/151

\begin{abstract}
MATERIAL AND METHODS
Study Design

This was a retrospective study conducted by the Department of General Surgery at a Tertiary Care Medical College Hospital Udaipur, (Rajasthan), India, over a period of 2 years (Jan 2013 - Dec 2014). Total of 30 patients who underwent exploratory laparotomy for perforation peritonitis and intestinal obstruction with creation of temporary loop ileostomy, barrel ileostomy and end ileostomy was studied. After 8 weeks' time simple closure of ileostomy and anastomosis of ileal stoma by end-to-end and ileo-transverse was performed.
\end{abstract}

\section{Patients}

Retrospective data of ileostomy created patients were collected from medical record department of the hospital. Most of the patients falling in age range of 31-75 years 22 patients $(73.33 \%)$. Total 30 patients diagnosed as a case of perforation peritonitis and intestinal obstruction underwent exploratory laparotomy with creation of loop ileostomy, barrel ileostomy and end ileostomy temporary or permanent was done according to the situation and subsequent closure after a period of 8 weeks, and the final diagnosis was made after a report of histopathology.

All the patients were clinically evaluated by detailed history, routine examination and following investigations were done. Complete blood count, BT, CT, renal function test, blood sugar, LFT, PT/INR, serum electrolytes, serum protein, 
Widal test, typhidot test, blood culture, X-ray chest and X-ray flat plate abdomen (erect), ultrasonography and CECT (IV and oral contrast) of whole abdomen. Before closure of ileostomy loopogram, barium enema colonic region and CECT was done.

\section{METHODS}

The time spent for preparation and correction of dyselectrolytemia was 5 to 6 hours. Patients having pre renal failure were subjected to dialysis 1 case (3.33\%). One patient $(3.33 \%)$ was having deranged coagulation profile and raised INR was transfused FFP and blood to achieved correction. Two cases $(6.66 \%)$ had comorbid medical conditions with hypertension and IHD and cardiac assessment was done. Adequate antibiotics cover given in all cases.

Delay in presentation and hospital admission noted which was ranging from 12 hours to more than 72 hours and maximum patients were admitted in 48 to 72 hours 22 cases (73.33\%).

Exploratory laparotomy with construction of ileostomy was done under general anaesthesia, operative findings were recorded and stoma was created at standard site. All ileostomies were carefully managed by dietary advises and medication for reducing effluent and with adequate local skin care. Ileostomies were closed after 8 weeks. All the problems and complications during intervening period till the ileostomy closure were managed accordingly. Patients were discharged on 7 to 10 days and asked to report for followup after 3 weeks.

\section{STATISTICAL ANALYSIS}

The significance of data was evaluated by applying the Chi. square test and $P$. value of less than 0.05 was considered statistically significant.

\section{RESULT}

Total of 30 patients who underwent exploratory laparotomy for perforation peritonitis and intestinal obstruction were observed. Total number of perforation were in 21 cases (70\%), among these perforation aetiopathology were typhoid perforation 9 cases (30\%), blunt trauma abdomen 6 cases (20\%), perforated tubercular ileum 3 cases (10\%), intestinal obstruction with perforated gangrenous ileum 3 cases (10\%); 9 cases (30\%) were presented with intestinal obstruction and aetiopathology were malignancy of colon/rectum 4 cases (13.33\%), mesenteric vascular thrombosis with gangrenous ileum 2 cases $(6.66 \%)$ and fulminating necrotic colitis 3 cases $(10 \%)$. In majority of the cases $80 \%$, there was severe degree of contamination, inflammation and edematous ileum (Table No:-1 and 2 Fig. No:-1).

\begin{tabular}{|c|c|c|}
\hline $\begin{array}{c}\text { Sl. } \\
\text { No. }\end{array}$ & Characteristics & $\begin{array}{c}\text { Total } \\
\text { Frequency (\%) }\end{array}$ \\
\hline $\mathbf{1 .}$ & Age (31-75 yrs.) & $22(73.33)$ \\
\hline $\mathbf{2 .}$ & Sex (M:F) & $13: 17$ \\
\hline $\mathbf{3 .}$ & $\begin{array}{c}\text { Presence of shock and } \\
\text { septicemia }\end{array}$ & $2(6.66)$ \\
\hline $\mathbf{4 .}$ & $\begin{array}{c}\text { Delay in presentation (>2 days } \\
(48-72 \text { hrs.) }\end{array}$ & $22(73.33)$ \\
\hline $\mathbf{5 .}$ & $\begin{array}{c}\text { Comorbid medical condition } \\
\text { (Hypertension / IHD) }\end{array}$ & $2(6.66)$ \\
\hline $\mathbf{6 .}$ & Severe degree of contamination & $24(80)$ \\
\hline $\mathbf{7 .}$ & Post-operative stay & $7-10$ days \\
\hline $\mathbf{8 .}$ & \multicolumn{2}{|c|}{ Mable 1: Patient Characteristics (n=30) } \\
\hline \multicolumn{2}{|c|}{}
\end{tabular}

\begin{tabular}{|c|c|c|c|}
\hline $\begin{array}{l}\text { Sl. } \\
\text { No. }\end{array}$ & Types of Surgery \& Stoma & $\begin{array}{c}\text { Frequency } \\
\text { (\%) }\end{array}$ & $\begin{array}{l}\text { Total } \\
\text { Frequency } \\
(\%)\end{array}$ \\
\hline 1. & $\begin{array}{l}\text { Perforation site exteriorized (Loop Ileostomy) } \\
\text { a) Enteric perforation. } \\
\text { b) Blunt Trauma Abdomen. }\end{array}$ & $\begin{array}{l}9(30) \\
6(20)\end{array}$ & $15(50)$ \\
\hline 2. & $\begin{array}{l}\text { Resection of ileum } \\
\text { a) Resection of perforated gangrenous ileum with barrel ileostomy in } \\
\text { intestinal obstruction. } \\
\text { b) Resection of perforated tubercular ileum with temporary end } \\
\text { ileostomy. } \\
\text { c) Resection of gangrenous ileum with temporary end ileostomy in } \\
\text { mesenteric vascular thrombosis. }\end{array}$ & $\begin{array}{l}3(10) \\
3(10) \\
2(6.66)\end{array}$ & $8(26.66)$ \\
\hline 3. & $\begin{array}{l}\text { Resection of total colon (Colectomy) } \\
\text { a) Colectomy with permanent end ileostomy in multiple polyposis with } \\
\text { carcinoma rectum. } \\
\text { b) Colectomy with permanent end ileostomy in fulminating necrotic } \\
\text { colitis. }\end{array}$ & $\begin{array}{l}3(10) \\
1(3.33)\end{array}$ & $4(13.33)$ \\
\hline 4. & $\begin{array}{l}\text { Right sided hemicolectomy } \\
\text { a) Right hemicolectomy with closure of transverse colon and temporary } \\
\text { end ileostomy in fulminating necrotic colitis. } \\
\text { b) Right hemicolectomy with omentectomy and temporary end ileostomy } \\
\text { in carcinoma ascending colon. }\end{array}$ & $2(6.66)$ & $3(10)$ \\
\hline & Table 2: Types of Surgery and indication of emergency ileostc & $y n=30$ & \\
\hline
\end{tabular}




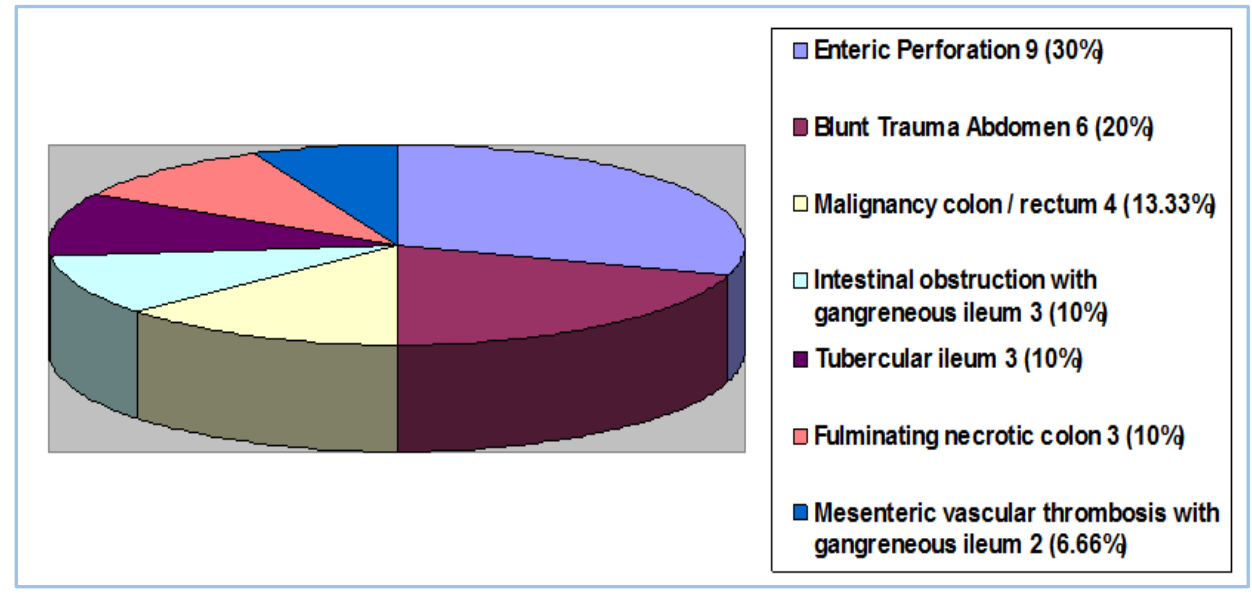

Fig. 1: INDICATIONS OF ILEOSTOMIES

Maximum patients were falling in age range 31-75 years 22 cases (73.33\%), there were 17 females (56.66\%) and 13 males (43.33\%). Creation of ileostomy was done as temporary loop ileostomy 15 cases (50\%), temporary end ileostomy 8 cases (26.66\%), permanent end ileostomy 4 cases (13.33\%) and barrel ileostomy 3 cases (10\%) (Fig. No. 2).

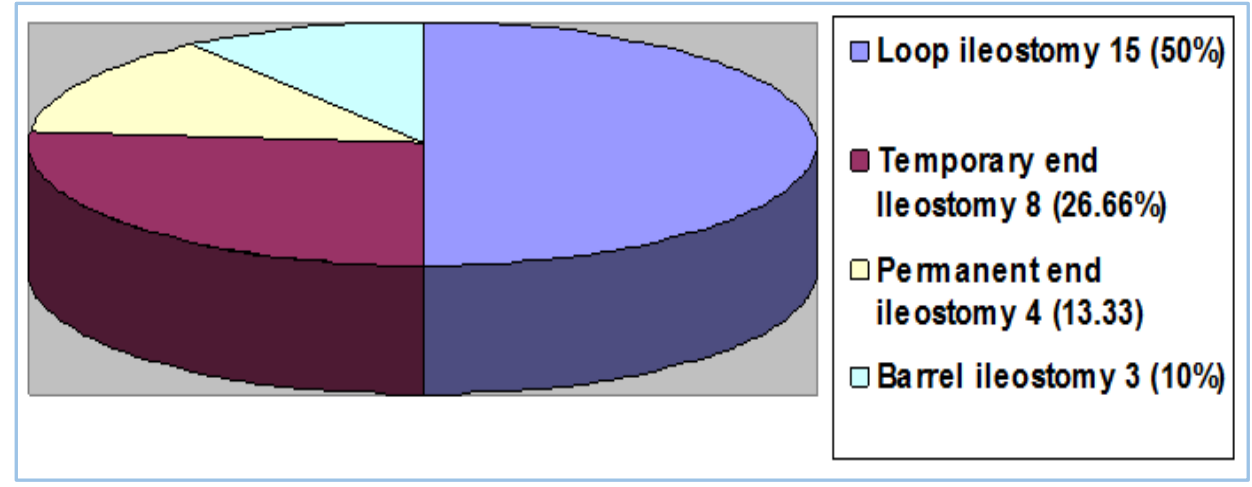

Fig. 2: TYPES OF STOMA

Their presenting complaints were fever, vomiting, pain abdomen, constipation and two patients presented in shock and septicemia having severely deranged renal function tests and raised INR. Morbidity related to stomal was skin excoriation 6 cases (20\%), excessive effluent 6 cases (20\%), ileostomy retraction 1 case (3.33\%), ileostomy prolapse 1 case (3.33\%), superficial bleeding from margin 1 case (3.33\%) and morbidity related to non-stomal was wound sepsis 6 cases (20\%), chest infection 5 cases (16.66\%), fluid and electrolyte imbalance 3 cases (10\%) minor anastomotic leak 2 cases (6.66\%), wound dehiscence on case (3.33\%) and major leak with faecal fistula and wound gap 1 case (3.33\%) (Table No. 3).

\begin{tabular}{|c|c|c|}
\hline Types & Complication & Frequency (\%) \\
\hline Stomal & $\begin{array}{ll}\text { 1. } & \text { Skin excoriation. } \\
\text { 2. } & \text { Excessive effluent. } \\
\text { 3. } & \text { Retraction. } \\
\text { 4. } & \text { Prolapse. } \\
\text { 5. } & \text { Superficial bleeding } \\
& \text { from margin. } \\
\end{array}$ & $\begin{array}{c}6(20) \\
6(20) \\
1(3.33) \\
1(3.33) \\
1(3.33)\end{array}$ \\
\hline $\begin{array}{l}\text { Non } \\
\text { Stomal }\end{array}$ & $\begin{array}{ll}\text { 6. } & \text { Wound Sepsis. } \\
\text { 7. } & \text { Chest infection. } \\
\text { 8. } & \text { Fluid \& electrolyte } \\
\text { imbalance. } \\
\text { 9. } \\
\text { Minor anastomotic } \\
\text { leak. } \\
\text { 10. Wound dehiscence. } \\
\text { 11. Major leak and } \\
\text { faecal fistula. }\end{array}$ & $\begin{array}{c}6(20) \\
5(16.66) \\
3(10) \\
2(6.66) \\
1(3.33) \\
1(3.33)\end{array}$ \\
\hline
\end{tabular}

These leakage were spontaneously healed and closed. Only 1 case $(3.33 \%)$ died after one month of surgery due to fulminating necrotic colitis superadded cytomegalovirus infection. Technique used in closure of loop and barrel stoma was hand sewn interrupted single layer with 3-0 Vicryl suture
18 cases (60\%) and linear stapler was used in side-to-side ileotransverse anastomosis for closure of temporary end ileostomy 8 cases $(26.66 \%$ ) (Table No. 4 ).

\begin{tabular}{|c|c|c|}
\hline Sl. No. & Type/Technique & Frequency \% \\
\hline 1. & $\begin{array}{c}\text { Simple closure in loop } \\
\text { ileostomies (Hand sewn) }\end{array}$ & $15(50)$ \\
\hline 2. & $\begin{array}{c}\text { Ileo-transverse side-to-side } \\
\text { anastomosis in temporary } \\
\text { end ileostomies (Stapler) }\end{array}$ & $8(26.66)$ \\
\hline 3. & $\begin{array}{c}\text { End-to-end anastomosis in } \\
\text { barrel ileostomies (Hand } \\
\text { sewn) }\end{array}$ & $3(10)$ \\
\hline 4. & Permanent end ileostomies & $4(13.33)$ \\
\hline \multicolumn{3}{|c|}{ Table 4: Surgery for stoma closure $\mathbf{n = 3 0}$} \\
\hline \multicolumn{2}{|c|}{} \\
\hline
\end{tabular}

\section{DISCUSSION}

The first surgical stoma was created more than 200 years ago, the earliest stomas were actually unintentional ones, enterocutaneous fistulas resulting from penetrating abdominal injuries or complications of intestinal diseases, such as incarcerated hernia.(1) 
In developing countries including India, intestinal perforation resulting from enteric fever and tuberculosis has always been a concern because of their high morbidity and mortality. $(4,5)$ In these cases, most perforations occur in the terminal ileum. Enteric fever is still a common cause of perforation in our country followed by tuberculosis being common disease of India.(2,3)

Enteric fever is endemic in India with the prevalence rate of 88 cases/lac population and death rate 0.029/lac population for the year 2011.(6) The present study of ileostomy was specifically conducted in order to record the various surgical settings requiring it and the ensuing post-operative morbidity situations that patient had to undergo before being put-up for a final ileostomy closure. The study was designed to outline the whole journey for patient of ileostomy.

The commonest aetiopathology was enteric perforation in our study $30 \%$, fairly comparable with the series Sushil et al. 36.67\%.(7) Qamar A et al. 31\%.(8) and Nadkarni et al. 25\%.(9) The next common indication that required ileostomy was traumatic perforation $20 \%$, while in series P. Chaudhary et al.

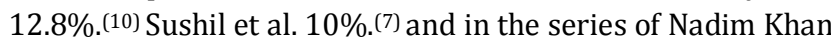
et al. 40.6\%.(11) Indication in cases of malignancy colon and rectum $13.33 \%$ observed high as compared with series Nadim Khan et al. 1.29\%.(11) and Qamar A et al 5.5\%.(8) The high incident in our series due to referred cases in the Cancer Center in our institute. Another aetiopathology was tuberculosis $10 \%$, fairly comparable with the series of Nadkarni et al. 9.3\%.(9) P. Chaudhary et al. 17\%.(10) Sushil et al. $18.33 \%{ }^{(7)}$ and Wani et al. $4 \%{ }_{.1}^{(12)}$

Indication of ileostomy in intestinal obstruction with gangrenous ileum $10 \%$, which was comparable with series of P. Chaudhary et al. 6.5\%.(10) and Wani et al. 6\%.(12) Aetiopathology was fulminating necrotic colitis in 3 cases $(10 \%)$, out of 3 cases total colectomy with permanent end ileostomy in one case and right hemicolectomy with temporary end ileostomy in two cases. While in series of K. Koss et al.(13) Total colectomy with end ileostomy was performed in 9 patients. Left hemicolectomy in 4 patients and right hemicolectomy in one patient in the series of 14 cases of fulminating necrotic colitis. Mortality in our series was one case of fulminating necrotic colitis and the cause of death was multi-organ failure, fairly comparable with the series of $\mathrm{K}$. Koss et al. was $35.7 \%$ and all 5 cases died due to multiple organ failure out of 14 cases.

Lastly, the indication of ileostomy in mesenteric vascular thrombosis with gangrenous ileum $6.66 \%$, in which resection of gangrenous ileum with temporary ileostomy was done, where with series of K. Vaghollcar, et al.(14) resection anastomosis of ischemic segment with proximal ileostomy was done in 3 cases out of total 10 cases of mesenteric vascular gangrene of ileum, which was not comparable with our series because of only two cases of mesenteric vascular gangrenous ileum was observed in our series, resection and anastomosis was not performed due to high contamination, oedematous and inflamed ileum with comorbid medical conditions hypertension and IHD in both the cases.

In our study preference was given to temporary ileostomy over primary closure or resection and anastomosis with proximal ileostomy because of severe degree of contamination, inflammation and edematous ileum observed with co-morbid medial conditions and septicemic shock.
Onset of symptoms and time of presentation in hospital are important prognostic factors. An early presentation holds a good prognosis. In developing countries like India, the presentation to hospital is late with blown peritonitis, septicemia and multiorgan failure.(15) In our study most of the patients falling in age range of 31-75 years (73.33\%) and male and the female ratio (13:17), which is unusual with other series.

Complication rate of temporary ileostomy ranges between $5-100 \%$. These rates vary due to varying length of follow-up. ${ }^{(1,16,17)}$ In our study the morbidity rate related to stomal and non-stomal was $50 \%$ which is fairly comparable with the series P. Chaudhary et al. 52.5\%.(10) and Andivox T, et al. 20-60\%.(18) In our series stomal related morbidity was skin excoriation 20\%. Fairly comparable with series of $\mathrm{P}$. Chaudhary et al. $20 \%$ with series of Sushil et al. $33.33 \%$ and with series of Qamar A et al. 39\%.(8)

Excessive effluent 20\% comparable with the series of Qamar A. et al. 16.6\% and with P. Chaudhary et al. 12.3\%. Retraction of stoma $3.33 \%$ comparable with the series of Qamar A. et al. 8.3\%, P. Chaudhary 6.6\% and in Sushil et al. $13.33 \%$, which was higher side as compared with our series. Prolapse of stoma $3.33 \%$ observed in our series fairly comparable with series of Sushil et al. 3.33\%, with Qumar A et al. $8.3 \%$ and with P. Chaudhary et al. $0.7 \%$.

Superficial bleeding from stomal margin $3.33 \%$ noted in our series also fairly comparable with series P. Chaudhary et al. 3.6\% and with Qamar A, et al. 2.7\%. Non-stomal related morbidity observed in our series was wound sepsis $20 \%$, comparable with series Sushil et al. 36.67\% and with Qamar A et al. $14 \%$. Chest infection $10.66 \%$ fairly comparable with series P. Chaudhary et al. 10.15\%. Fluid and electrolyte imbalance found in $10 \%$ of the cases and $6.66 \%$ of our patients needed aggressive fluid and electrolyte management preoperatively and during the $3^{\text {rd }}$ to $4^{\text {th }}$ post-operative days and commonly observed in cases with typhoid perforation, fairly comparable with series P. Chaudhary et al. $12.6 \%$ and $3.4 \%$ needed aggressive therapy and also comparable with series Sushil et al. $10 \%$ and the series Ambreen Muneer, et al.(19) $5.8 \%$ required aggressive therapy. Anastomotic leak (Minor) $6.66 \%$ and major leak with faecal fistula $3.33 \%$ was noted in our series and fairly comparable with series Sushil et al. $6.67 \%$.

Wound dehiscence $3.33 \%$ comparable with the series P. Chaudhary et al. $10.31 \%$ and Sushil et al. $13.33 \%$, which was higher as compared with our series. The major complications observed in our study was skin excoriation $20 \%$, excessive effluent $20 \%$, wound sepsis $20 \%$, chest infection $10.66 \%$, fluid and electrolyte imbalance $10 \%$, wound dehiscence $3.33 \%$, minor anastomotic leak $6.66 \%$ and major leak with faecal fistula $3.33 \%$ and higher morbidity observed in patients with enteric fever, tuberculosis, mesenteric vascular thrombosis, fulminating necrotic colitis, delayed presentation, poor nutritional status, co-morbid medical conditions, hypertension, IHD and patients admitted in septic shock.

Associated factors like improper sitting, bony prominences, pose a problem in proper placement of appliances which resulted infrequent leakage of bag and spillage of relatively watery effluent from the bag, due to improper post-operative care and poor nutrition. In our series all the complication were treated conservatively. Anastomotic minor leak one case and major with faecal fistula one case that 
healed over a period of time and no surgical intervention was required. While compared with series, Wexner SD, et al.(20) complication rate of $41 \%$ associated with loop ileostomy construction with $6 \%$ of patient requiring surgical intervention has been reported and with series Hall Book 0 , et al.(21) has a complication rate of $25 \%$ and all required surgical intervention.

In our series, one case $3.33 \%$ had a sequential surgical complication as fulminant septicemia, ARDS and multiple organ dysfunction, eventually succumbed in ICU on $30^{\text {th }}$ day.

\section{CONCLUSION}

In our series 50\% ileostomy was indicated in enteric and traumatic perforation, remaining $50 \%$ was performed in gangrenous ileum, tubercular ileum, malignancy rectum/colon and in fulminating necrotic colitis.

Temporary defunctioning ileostomy helps to reduce morbidity and mortality in patients undergoing surgery for ileal perforation. Higher morbidity observed in patients with enteric perforation, tuberculosis, mesenteric vascular thrombosis with gangrenous ileum, fulminating necrotic colitis, delayed presentation, poor nutritional status, comorbid conditions and patients admitted in septic shock.

Important complications included skin excoriation, excessive effluent, fluid and electrolyte imbalance wound sepsis and chest infection. Early presentation in hospital, early diagnosis and treatment of enteric fever, tuberculosis, malignancy of rectum/colon and avoidance of trauma can be reduce emergency stoma creation and associated morbidity.

\section{REFERENCES}

1. Kaider-person 0, Waxner SD. Complications of construction and closure of temporary loop ileostomy. J Am Coll Surgery 2005;201:759-773.

2. Duchesne JC, Wang YZ, Wentraub SL, et al. Stoma complication: a multivariate analysis. Am J Surgery 2002;68:961-966.

3. Hussain T, Alam SN, Manzar S. Outcome of ileostomy in case of small bowel perforation. Pak J Surgery 2005;21:6571.

4. Butler T. Typhoid fever. In Cecil's text book of medicine, 20th ed, Philadelphia, WB Saunders 1996;P1641-1646.

5. Aston No. Abdominal tuberculosis. World J Surgery 1997;21:1972-499.

6. Govt. of India (2012). National health profile 2011, DGHS, Ministry of health and family welfare, New Delhi.
7. Sushil Mittal, Harman Singh, et al. A comparative study between the outcome of primary repair versus loop ileostomy in ileal perforation. Surgery Research and Practice (Hindawi) Volume 2014;10:11-55.

8. Qamar A Ahmed, et al. "Indications and complication of intestinal stomas - a tertiary care hospital experience." Biomedica Vol. 26, July-Dec 2010; Bio-11. Doc P144-147 (WC).

9. Nadkarni FM, et al. Small bowel perforation. "A study of 52 cases." Archives surgery 1981; Vol. 116, pp. 53-57.

10. Poras Chaudhary, et al. Prospective analysis of indications and early complications of emergency temporary loop ileostomies for perforation peritonitis. Annals of Gastroenterology 2014;27:1-6.

11. Nadim Khan, et al. "Is early closure of stoma warranted in the management of temporary loop ileostomy." JPMI 2010; Vol. 24, No. 04: 295-300.

12. Wani RA, et al. "Non-traumatic terminal ileal perforation." World J of Emergency Surgery 2006; Vol. 24, No. 1, article 7.

13. Koss $\mathrm{K}$, et al. The outcome of surgery in fulminant Clostridium difficile colitis (C) 2005 Blackwell Publishing Ltd. Colorectal disease 8:149-154.

14. Vagholkar K, et al. Acute mesenteric ischemia: an abdominal calamity. The Internet Journal of Gastroenterology. 2014; Vol. 13, No. 1-8.

15. Malik AM, Laghari AA, Mallah Q, et al. "Different surgical options and ileostomy in typhoid perforation." World Journal of Medical Sciences 2006; Vol. 1: PP112-116.

16. Arumugam PL, et al. A prospective audit of stomas-analysis of risk factors and complications and their management. Colorectal Dis 2003;5:49-57.

17. Robertson I, et al. Prospective analysis of stoma related complications. Colorectal Dis 2005;279-285.

18. Andivox T, et al. Complications of colostomies - followup study of 500 colostomized patients, Ann Chir 1996;50:252257.

19. Ambreen Muneer, et al. 2007. Various complications in ileostomy construction. World Applied Sciences Journal 2007;2(3):190-193.

20. Wexner SD, et al. Loop ileostomy is a safe option for fecal diversion. Dis Colon Rectum 1993;36:349-354.

21. Hallbook 0, et al. Safety of temporary loop ileostomy. Colorectal Dis 2002;4:361-364. 